\title{
Humano, Demasiadamente humano: SOBRE EMOÇÕES E MASCULINIDADE ${ }^{1}$ \\ (Human, too Human: On emotions and masculinity)
}

Sônia Maria de Oliveira Pimenta

(UFMG)

Cláudia Natividade

(UFMG)

Resumo: Com base na Semiótica Social e na multimodalidade, este artigo analisou quatro propagandas das edições de março de 2005 da revista Veja nas quais figuravam homens de diferentes idades e em diferentes contextos. Dentro dessa concepscão sócio-semiótica, pretendeu-se identificar os potenciais de significados veiculados por vários modos semióticos relacionados com a função interpessoal da linguagem, ligando-os a conteídos emocionais. Inanguramos uma perspectiva diferenciada de análise do signo da emoção propondo categorias analíticas multimodais complementares àquelas disponiveis na literatura (Kress $\mathcal{E}$ van Leenwen, 2006). Os resultados indicam que as propagandas fazem parte do projeto de engajamento da masculinidade hegemônica com conteúdos de poder e ausência de emoģões.

Palavras-chave: Semiótica Social, multimodalidade, emoções, masculinidade.

Abstract: This article analyzed four advertisements of Veja magazine 2005 (March edition), based on Social semiotics and multimodality, in which men of different ages and context appeared as represented participants. In a social semiotic perspective, the aim of the paper was to identify the meaning potentials expressed by different interpersonal semiotic modes, related to emotional contents. We have proposed a different analytical perspective of the emotion sign creating categories of multimodal analyses, which complemented those already, available in the literature (Kress $\&$ van Leenwen, 2006). The results revealed the advertisements as a product of the engagement at hegemonic masculinity based mainly on power and lack of emotions.

Key-words: Social semiotics, multimodality, emotions, masculinity.

1. Título parafraseando da obra de Nietzsche "Humano, demasiado humano" em que o autor escreve por aforismos e coloca ideias que seriam refinadas em seus escritos posteriores.

D.E.L.T.A., 28:Especial, 2012 (605-637) 


\section{INTRODUÇ̃̃O}

Este artigo pretende apresentar um estudo sobre as emoções humanas com base em Teorias Sociais de Discurso, especialmente a Semiótica Social, tentando, dessa forma, suprir, ao menos parcialmente, uma carência nessa área de estudos. É importante salientar que, ao iniciarmos o trabalho sobre as emoções, uma das questões cruciais com que nos deparamos foi a existência de distintas abordagens teóricas sobre o tema: psicológicas, sociológicas, antropológicas, discursivas ou linguísticas, que gravitam em torno de uma distinção básica: as concepções dualistas e as isolacionistas (ELIAS, 1991). As teorias isolacionistas consideram as emoções como expressões corporais com uma grande disposição biológica sendo, portanto, equivalentes às emoções dos animais. As concepções dualistas, por outro lado, tratam das emoções ligadas ao corpo, com duas dimensões complementares: o corpo físico, que é o veículo da expressão das emoções, e o corpo social, fruto da aprendizagem em grupo (social, cultural, étnico, de gênero, de geração e outros). A primeira concepção não liga a natureza com a vida em grupo e trata as emoções como "padrões de reações geneticamente fixadas" (ELIAS, 1991:104). Já na concepção dualista, três componentes das emoções são considerados: o fisiológico, o comportamental e o de sentimento, englobando, assim, as dimensões objetivas e subjetivas desse fenômeno.

Neste artigo, partimos do pressuposto de que as emoções devem ser estudadas dentro de uma concepção sócio-semiótica, pois possuem função central nas vivências humanas, uma vez que são (re)produzidas no palco das interações. Para tanto, optamos pela utilização de uma abordagem semiótica e multimodal das emoções. Temos, no entanto, a clareza de que todas as outras abordagens mencionadas acima servem de alicerce para nossa proposta de análise das emoções humanas. A abordagem semiótica refere-se ao processo de significação como parte da construção social, considerando a circulação de significados com origens, funções, contextos e efeitos localizados cultural, histórica e ideologicamente (Hodge \& KREss, 1988). Pretendemos inaugurar uma perspectiva diferenciada de análise das emoções, já que grande parte delas se baseia em conceitos psicológicos, sociológicos e antropológicos. Nesse sentido, o foco principal desse artigo é a construção semiótico-social do signo da emoção, dentro de um princípio multimodal que confere poder de representação e comunicação aos diferentes modos semióticos disponíveis em nossa vasta paisagem semiótica. 
Podemos afirmar que o maior instrumento de comunicação das emoções é a face, na qual se encontram fixadas as experiências humanas e, principalmente, aquelas relacionadas com os sentimentos. O sinal da face mais conhecido é o sorriso. Por isso, com a intenção de esboçar um primeiro estudo semiótico sobre o signo da emoção, elegemos o significante/ modo semiótico sorriso como o principal instrumento de identificação dos diferentes significados do signo da emoção. Tal decisão fez com que necessitássemos criar uma nova categoria para a análise multimodal, categoria essa que denominamos comportamento emocional, de modo a contemplar os significados potenciais identificados no corpus de análise, no qual figuram vários tipos de sorrisos, como veremos na seção de análise.

Bell (2001), com base no trabalho de Goffman, já havia proposto uma categoria denominada comportamento para fazer o mapeamento de modos semióticos corporais de uma forma ampla, tais como a posição da cabeça e do corpo, a envergadura dos joelhos etc. Contudo, como os potenciais de significado dessa categoria são muito amplos, foi necessário delimitarmos nossas análises, focalizando-as num modo semiótico que contemplasse os componentes de trocas emocionais equivalentes às funções semióticas de demanda e de oferta da metafunção interpessoal. Essa metafunção, que leva a marca da interação, não poderia deixar de ter uma categoria que incluísse o aspecto emocional, já que toda relação humana supõe trocas em vários níveis.

Nas análises do corpus, outros modos semióticos serão chamados a dialogar no mesmo nível ou em níveis diferentes com a categoria "comportamento emocional" que propusemos acima, tomando posições ora de contraste, ora de reforço na construção discursiva. Para tanto, selecionamos quatro textos publicitários de todas as edições do mês de março/2005 da revista Veja, nos quais figuravam homens sozinhos, de diferentes idades, utilizando o modo semiótico sorriso. Escolhemos trabalhar com as representações midiáticas por considerá-las um importante aspecto na sociedade moderna de veiculação e construção de significados, principalmente aqueles relacionados com as identidades sociais. Para Sabat (1999), a mídia exerce uma função pedagógica, na medida em que representa tecnologias do "eu" (a reflexão sobre si mesmo, principalmente sobre o corpo e sobre os modos do ser) e estratégias de linguagem congruentes com as práticas de subjetivação. 
Optamos, também, por analisar as representações de masculinidade, por entendermos que a socialização dos homens evidencia conexões diretas com o controle da expresão de emoções, com o objetivo de atingir mandatos sociais específicos, como veremos na seção dois deste artigo. Essa análise de um corpus publicitário sobre emoções masculinas - faz parte de uma pesquisa maior ${ }^{2}$, na qual nosso intuito é contrastar as expressões midiáticas sobre emoções masculinas com outros tipos de corpora verbais e visuais. A expressão de emoções no espaço público é um tópico de frequente discussão entre os homens e vem sendo abordado pelas nossas pesquisas de interação face a face anteriores e em andamento. De acordo com a semiótica social, investigar um tópico de forma comparativa em diferentes corpora delineia os diferentes processos de significação, suas origens e funções, construídas em diversos contextos.

\section{2. “OS INUMERÁVEIS ESTADOS DO SER" ${ }^{3}$ OU OS VÁRIOS APORTES TEÓRICOS SOBRE EMOÇÕES}

O dicionário Aurélio virtual define o verbete emoção como "um distúrbio, uma excitação, o aspecto afetivo da consciência, um sentimento, um estado de sentimento, uma reação psíquica e física (como raiva ou medo) subjetivamente e fisiologicamente forte, envolvendo mudanças que preparam o corpo para ação vigorosa imediata" Constatamos, assim, que o aporte teórico vigente sobre as emoções focaliza os aspectos psicológicos do termo e passa a definir emoções como respostas dadas a um evento ambiental específico, possuindo um caráter de reatividade.

Frequentemente, as teorias psicológicas representam o aparelho psíquico como algo repleto de pressões emocionais, sendo as relações parentais fundamentais nas experiências das pessoas. Um dos problemas dessas teorias

\footnotetext{
2. Pesquisa de interação face a face já concluída: NATIVIDADE, Cláudia e PIMENTA, Sônia. Debate entre gêneros: possibilidades de construção sobre o signo das emoções masculinas. In: MENDES, Emília e MACHADO, Ida Lúcia (orgs). As emoções no discurso. Vol II. Campinas, SP: Mercado das Letras, 2010; e pesquisa em andamento: "Semióticas da masculinidade e as relações de gênero entre homens que exercem violência contra mulheres" projeto de doutorado de Cláudia Natividade sob orientação da professora Sônia Pimenta.

3. Frase de Antonin Artaud apropriada por Nise da Silveira que a interpretou como se referindo aos diversos acontecimentos inconscientes das pessoas e seus potenciais de organização e desorganização do ser.
} 
é que elas focalizam o desenvolvimento humano individual e tomam as emoções como feridas que foram provocadas em um determinado momento e que precisam de uma reparação.

Durante boa parte do século XX, as emoções permaneceram como um assunto prioritário da psicologia, sendo consideradas como realidades psicobiológicas com caráter subjetivo de desenvolvimento. Somente a partir da década de 1980 é que elas voltam a ganhar espaço nas ciências sociais e, em particular, na antropologia. Rezende (2002:70) discute a antropologia das emoções e adiciona à sua definição o caráter situacional em termos de gênero, idade, raça, classe social e fase da vida do indivíduo, tratando-as "como práticas discursivas permeadas por negociações de poder". Segundo ela, pensadores clássicos como Durkheim e Simmel inauguraram a discussão sobre a dimensão social, garantindo um caráter sociológico, mas não cultural, das emoções. Em suas análises, a autora comenta que Durkheim define as emoções como uma forma de organização humana e Simmel, como um processo oriundo da interação social dos indivíduos.

Ainda para Rezende (2002), dentre os estudos antropológicos mais importantes, foi o de Mauss ${ }^{4}$ que desenvolveu a análise mais aprofundada da constituição das emoções enquanto fato social. Partindo do pressuposto de que há uma estreita conexão entre as dimensões biológica, psicológica e social das emoções dos seres humanos - tanto na sua expressão oral quanto gestual e corporal -, Mauss acrescenta que elas formam uma linguagem, signos de expressões compreendidas que, em muitas situações, pressupõem manifestação obrigatória. Com tal argumento, esse autor enfatiza a necessidade de se compreenderem as emoções como elementos de comunicação e, portanto, como elementos eminentemente sociais.

Mais recentemente, conforme pontua Rezende (2002), as abordagens antropológicas de estudo das emoções ganharam dimensão contextual mais acentuada, buscando ir além das relativizações e analisá-las de um ponto de vista discursivo, nas situações sociais específicas em que elas são expressas. O foco no discurso é central também para as abordagens sociolinguísticas que, seguindo a inspiração de Foucault (1979, 1987, 1988), tratam os discursos como práticas que constituem os objetos sobre os quais elas discorrem, sendo permeadas por relações de poder. Nesse sentido, é

4. MAUSS, Marcel. A expressão obrigatória dos sentimentos. In: FIGUEIRA, S. A. (org) Psicanálise e ciências sociais. Rio de Janeiro: Francisco Alves, 1981. p. 56-63. 
fundamental para a compreensão do discurso, considerar o contexto em que ele é acionado - por quem, para quem, quando e com que propósitos. Partindo da noção de Foucault, Kress \& Van Leeuwen (2001) tomam os discursos como conhecimentos socialmente e culturalmente construídos e interpretados de algum aspecto da realidade. Nesse quadro, o discurso da emoção constitui uma forma de ação social que cria efeitos no mundo, ou seja, tem caráter político.

Com o intuito de descobrir os significantes e os significados das emoções masculinas e perceber a construção semiótica do signo das emoções masculinas, partimos do conceito encontrado no dicionário Visual Thesaurus 5 . O campo lexical do verbete emoção tem como ponto de partida o item sentimento, seguido por (uma) característica psicológica, desmembrandose em um amplo campo semântico com vários significados. Em nossa análise do corpus midiático, verificaremos a presença ou a ausência de tais significados e os modos semióticos utilizados na sua representação. Segundo nossa abordagem, a vasta gama semântica mostrada na figura abaixo representa significados socialmente e culturalmente produzidos/entendidos como positivos ou negativos, compondo uma paisagem semiótica sobre as emoções.

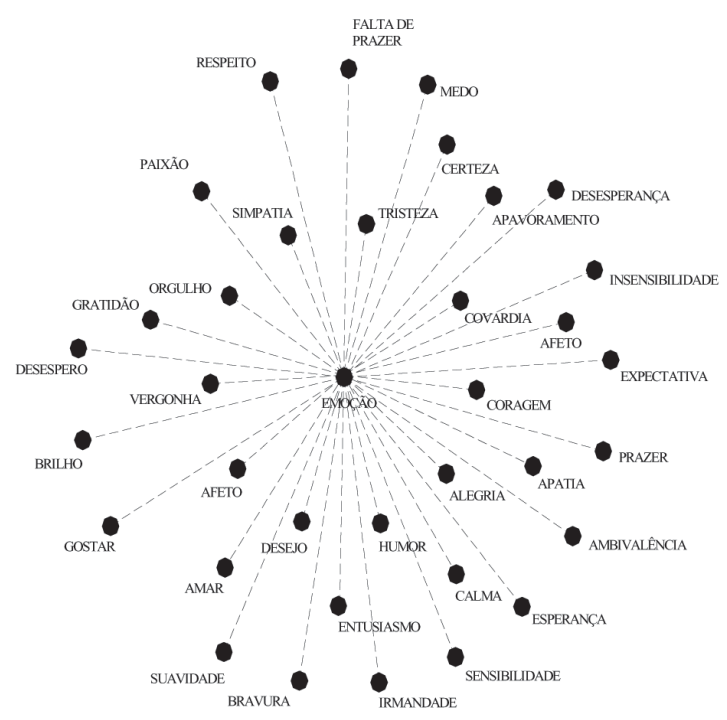

Figura 1: Verbete "emoção" do Visual Thesaurus

5. Disponível em http://visualthesaurus.com. Acesso em: 15 de setembro de 2008. 
Como neste artigo decidimos ater-nos aos significados produzidos por homens em textos publicitários, através do sorriso, partimos do conceito de emoção, dos significados mostrados na figura 1, de modo a evidenciar como o significante/modo semiótico do sorriso, juntamente com outros, permite-nos chegar ao signo da emoção masculina nessas publicidades e a seus diferentes significados. Tomamos, também, como ponto de partida o trabalho de Argyle (1975, ARGYLE \& COOK, 1976), um psicólogo social e grande estudioso da linguagem não-verbal (gestos, postura, olhar etc.), que conceitua o sorriso como sendo "a ação de rir sem ruído, apenas com leve contração dos músculos faciais, mostrando-se alegre”. Vemos, portanto, que, conforme ressaltamos acima, esse conceito expressa significados de sentimentos e emoções como prazer, excitação, entusiasmo, desejo, alegria, afeto, prazer, suavidade, amor, ambivalência, insensibilidade, desesperança, bravura e muitos outros. A partir da análise multimodal e semiótica dos anúncios selecionados, que examinaremos na seção 5 , será possível perceber esses significados, bem como os discursos produzidos em determinados contextos sociais, culturais, ideológicos e políticos, o que vai além das análises psicológicas, sociológicas e antropológicas. Perceberemos, também, como tais significados se ligam a diferentes modos semióticos e como estão relacionados à construção social da masculinidade

Cabe dizer, por fim, que, a partir de uma perspectiva sócio-semiótica, concebemos as emoções como fenômenos complexos que se constituem em várias dimensões, pois, além de possuírem um substrato biológico, são construídas através de processos psicológicos e estão inseridas em contextos históricos, culturais e sociais interativos e dinâmicos. Elas fazem parte de conteúdos internos, subjetivos dos seres humanos e se ligam, de forma dialógica, ao espaço social e objetivo, mantendo, com ele, integração e articulação constantes. Para a discussão dos aspectos emocionais envolvidos na construção da masculinidade, exploraremos, sobretudo, o processo de socialização vivenciado pelos homens como uma instância cultural, social, histórica e ideologicamente localizada. Com essa abordagem, buscamos alcançar uma análise sobre a experiência relacional dos homens, organizada a partir dos amplos processos sociais. Tal pesquisa poderá indicar algumas pistas sobre como as imagens veiculadas pela mídia se ligam a tais processos sociais e como eles influenciam a subjetividade dos homens. 


\section{Masculinidade(s) e emoções}

Sabemos o que significa ser um homem porque há uma representação da masculinidade como um conjunto de significados socialmente reconhecidos. Uma representação é um discurso, um modo de construção de sentidos que influencia e organiza as nossas ações, bem como a concepção que temos de nós mesmos (Hall, 1995). Poderíamos, porém, tentar uma definição de masculinidade que não seguisse tão somente traços essenciais ou normativos, mas que focalizasse principalmente as dinâmicas inerentes ao processo de socialização e subjetivação dos homens de forma expandida. Para isso, é fundamental perceber as características históricas de construção das masculinidades, bem como sua imbricação com estratos e sistemas simbólicos, ou seja, trata-se de um trabalho de mapeamento da interface entre as estruturas sociais, a experiência relacional e a subjetividade dos homens. A partir de uma abordagem semiótica e seguindo a influência dos estrudos pós-estruuralistas, nosso foco recai sobre a análise do sistema de diferença simbólica que envolve a constituição da(s) masculinidade(s), assim como os efeitos gerados por esses construtos nas relações e práticas dos sujeitos.

Quando relacionamos os estudos de gênero com tal perspectiva, chamamos ao diálogo Judith Butler (1990, 1993), que considera o gênero como um construto analítico com um caráter eminentemente performativo. Isso significa dizer que, para além de todas as possíveis construções sobre o gênero masculino - que podem tomar, em alguns contextos, contornos essencialistas indesejáveis -, nosso olhar deve procurar os efeitos e desdobramentos desse construto nas práticas e relações sociais, de forma ampla.

Um importante ponto a ser focalizado na discussão sobre os efeitos dos construtos tradicionais de masculinidade recai, inevitavelmente, sobre o processo de socialização dos homens, que inclui, desde a infância, a configuração de um ser forte, seguro de si mesmo, competitivo e vencedor. Para que tal projeto de masculinidade seja materializado, algumas condutas serão imprescindíveis: não chorar, não se mostrar fraco, com medo ou inseguro, ou seja, não demostrar emoções. Segundo Corsi (2006:15), "a identidade masculina tradicional é construída a partir de dois processos psicológicos simultâneos e complementares: o hiper desenvolvimento do eu exterior (fazer, atuar, conseguir) e a repressão da esfera emocional". Para conjugar as forças desses dois processos, os homens necessitam desenvolver autocontrole para regular a expressão de suas emoções. De acordo com o autor, a 
restrição emocional "consiste basicamente em não falar sobre os próprios sentimentos, especialmente com outros homens" e vem conjugada com atitudes baseadas no controle, no poder e na competência.

A centralidade da questão do poder na vida dos homens é enfatizada por autores como Connell (2005) e Kaufman (1993). Poder, na socialização tradicional masculina, pode ser traduzido como o estabelecimento de relações e práticas de subordinação para com aquele que é reconhecido como inferior. Obviamente, para o exercício do poder, é necessária a supressão de sentimentos. Kaufman (1993:7) afirma que "a experiência de poder dos homens é contraditória: junto com os privilégios há dor e isolamento" que, por sua vez, não podem ser expressos socialmente. Um sistema de hierarquia - outro ponto importante na construção social da masculinidade - gerencia essa dinâmica de emoções e de poder na qual este último prevalece sobre as emoções.

De acordo com Foucault (1988, p. 90), o poder não se localiza nas pessoas, nas instituições, nem na estrutura, porque é mais uma situação estratégica que se "exerce a partir de inúmeros pontos e em meio a relações desiguais e móveis". Ele é, pois, um construto relacional, gerador de efeitos e que resulta de redistribuições, alinhamentos, homogeneizações, arranjos de série e convergências (FouCAUlT, 1996). A coexistência entre emoções e controle na socialização masculina resulta na constituição de um lugar simbólico de exercício de poder (OliveIRA, 2004), regido, principalmente, pela racionalidade. Assim, há estreita relação entre a construção social e subjetiva da masculinidade e a razão.

Tradicionalmente falando, a construção da subjetividade masculina, a partir da sua identificação com a racionalidade, se encontra corporificada, principalmente, na esfera pública, na qual os homens são chamados a assumir atitudes de independência e auto-suficiência, que trazem como consequência o afastamento das necessidades afetivas em nome da razão. Segundo Seidler ${ }^{6}$ (1991), citado por Giffin (2005), a tentativa de ser este homem competitivo, racional, ambicioso, forte e independente frequentemente significa, no mínimo, distorcer sensibilidades e matar emoções. Tal construção social/tradicional de masculinidade fortalece a ética do trabalho

6. SEIDLER, V.J. Recreating sexual politics: men, feminism and politics. London - New York: Routledge. 1991. 
capitalista, na medida em que pode transformar corpos em máquinas produtoras/reprodutoras de controle e poder.

Da mesma forma, Connell (2005) amplia a discussão sobre as dinâmicas de classe, raça, nacionalidade e posição social, afirmando que o gênero - nesse caso, a masculinidade - parte de pressupostos hegemônicos, mas tem que ser considerado por meio de múltiplos diálogos. $\mathrm{O}$ autor afirma que a construção da masculinidade está combinada com a história das instituições e com a estrutura econômica da qual herdamos uma dinâmica global de dominação de uns em detrimento de outros, bem como o crescimento ostensivo de impérios empresariais que trazem o contexto de mercantilização da vida.

\section{A Semiotica Social e a multimodalidade}

Formulada por Kress \& Van Leeuwen (2001), a multimodalidade expande e amplia os conceitos da Semiótica Social apresentada por esses mesmos autores em seu livro Reading Images: the Grammar of Visual Design. Se antes as disciplinas teóricas e críticas eram monomodais, hoje essa posição começou a mudar. Isso porque as mais diversas formas de expressão cultural e artística têm usado uma grande variedade de materiais, atravessando as fronteiras antes existentes entre umas e outras e caminhando, assim, em direção, por exemplo, à criação de eventos multimídia (KRESS \& VAN LEEUWEN, 2006).

A semiótica social propõe o estudo do significado e da mensagem como ponto central, ao passo que a multimodalidade focaliza o estudo dos usos dos recursos semióticos e seus potenciais de significado a partir de diferentes origens e em diferentes contextos. Esses dois pontos, ou seja, o significado enquanto produção e o recurso enquanto representação, juntam-se de forma motivada na comunicação multimodal, na qual "princípios semióticos em comum operam dentre e por entre os diferentes modos" e, portanto, torna-se "bem possível para a música codificar a ação ou para a imagem codificar a emoção” (KRess \& VAN LeEUWEN, 2001:2). Assim, os princípios semióticos perpassam os diferentes recursos disponíveis (sorriso, olhar, gestos, iluminação, cor, postura, palavras etc.) na vasta paisagem semiótica e são escolhidos como formas de representação pelos atores sociais de uma mensagem, por serem mais expressivos num dado momento da comunicação. 
A linguagem multimodal é um fenômeno social, mais especificamente, uma forma de comportamento social que tem a função de comunicar algo. Para isso, opera dentro do sistema de interação humana permitindo-nos, portanto, a partir dela, investigar o relacionamento social. Dessa forma, quando escolhemos significados, somos orientados por aquilo que consideramos ser mais apto e plausível ${ }^{7}$ naquele momento e naquela cultura.

Entendemos, então, que o uso da linguagem está conectado com os contextos de situação e de cultura nos quais ela opera. Esse significado potencial da comunicação, entendido a partir da máxima "poder significar", é equivalente a "poder fazer" quando traduzido pela linguagem, e investigado a partir de escolhas multimodais. É importante ressaltar que os significados com que operamos em uma determinada interação, sejam eles palavras, gestos ou olhares (ou qualquer outro recurso semiótico), são conteúdos políticos, na medida em que são formas que se encontram organizadas por nossos relacionamentos em grupos sociais e culturais. O processo de semiose humana, ou seja, a produção, a reprodução e a circulação de significados moldados de várias formas, pressupõe o entendimento de que toda a comunicação é um ato de significação, uma tessitura de significados operados no nível do discurso.

Tematizando o processo de semiose das emoções, percebemos que Matthiessen (mimeo, 2006) as localiza no sistema da linguagem, conferindolhes o caráter de: (1) um fenômeno semiótico na pessoa e no grupo social com troca de significados; (2) um fenômeno social na pessoa e no grupo social - um comportamento interpessoal; e (3) um fenômeno biológico no organismo. Vale ressaltar que nossa proposta de análise entende as emoções como um fenômeno semiótico em um contexto social mais amplo do que o proposto por Matthiessen, uma vez que engloba os sistemas de poder, ideológico e político, como veremos na análise do corpus, seguindo a proposição da Semiótica Social de Hodge \& Kress (1988).

7. O termo técnico "mais apto" está relacionado ao mais disponível dentre todas as possibilidades do potencial de significado; já "mais plausível" se refere ao mais adequado para aquele momento e para aquela cultura. 


\section{DESVENDANDO AS REPRESENTAÇÕES SOBRE MASCULINIDADE: UMA LEITURA MULTIMODAL DA MÍDIA}

Optamos por desenvolver uma análise sócio-semiótica e multimodal de 4 textos publicitários das edições de março de 2005 da revista Veja. Do universo inicial de textos (186), 54 mostraram homens e 31, mulheres, o que equivale a menos da metade do total. Dentre os 54 anúncios em que o homem aparece como Participante Representado, elegemos quatro para fins de análise e exemplificação. De acordo com a Gramática do Design Visual, o Participante Representado é aquele presente na imagem, enquanto o Participante Interactante, ou interativo, é aquele com quem o Participante Representado dialoga por meio de diferentes modos semióticos, ou seja, o leitor. Na Gramática Sistêmico-Funcional hallidaiana, uma das categorias de análise utilizadas para desvelar as construções discursivas das emoções são as escolhas lexicais, as modalizações, os processos mentais e os grupos nominais que representam e comunicam significados ideacionais e interpessoais.

Analisaremos os anúncios a partir de três ângulos diferentes: diferença de idade, categorias interativas e marcadores de modalidade, como demonstrado a seguir:

1 - Diferença de idade, começando pela criança e chegando a um executivo, o mais velho do grupo.

2 - Categorias interativas

2.1 - Categorias interativas propostas por Kress e Van Leeuwen (2006):

- contato: que pode ser de demanda ou oferta, a partir da análise do modo semiótico do olhar;

- distância social: que pode ser íntima/pessoal, social e interpessoal, a partir da posição espacial na qual o participante representado está localizado;

- atitude: que pode ser objetiva ou subjetiva (naturalística ou não). 


\section{2 - Categoria interativa proposta pelas autoras:}

- comportamento emocional: que pode ser alto, médio e baixo, a partir da análise do modo semiótico do sorriso;

3 - Os marcadores de modalidade, como as cores, que geram orientações de códigos sensoriais, naturalísticos, tecnológicos e abstratos e conformidade de aparência;

3.1 - Marcadores de modalidade propostos por Kress e Van Leeuwen (2006):

- saturação: cores mais realçadas ou a ausência de cores, como preto e branco;

- diferenciação: do monocromático à escala diversificada de cores;

- modulação: do tom mais claro ao mais escuro.

3.2 - Marcador de modalidade proposto pelas autoras:

- conformidade de aparência: que pode ser baixa, média e alta (com mais ou menos poder), dependendo da vestimenta e de sua adequação com a idade, com os papéis sociais e com o grau de afiliação dos participantes representados.

Em primeiro lugar, a gradação de idades propiciará subsídios analíticodiscursivos para demonstrar o processo de socialização vivenciado pelos homens - de crianças a adultos. Em segundo lugar, as categorias interativas de comportamento indicarão as formas de engajamento dos participantes representados com os leitores, produzindo significados mais aproximados ou distantes de conteúdos emocionais, foco do nosso artigo. O leitor deste artigo observará que a categoria comportamento emocional não se encontra na literatura disponível, mais especificamente na gramática do design visual de Kress e Van Leeuwen (1996, 2006), pois ela surgiu como amplificação das categorias existentes, a partir das análises do corpus em questão. Salientamos que a proposição dessa categoria foi muito pertinente neste momento, pois sentíamos que os tópicos analíticos disponíveis não contemplavam totalmente os conteúdos interpessoais que visualizávamos no momento da análise. 
Em terceiro lugar, os marcadores de modalidade permitirão avaliar a produção de significados de verdade e realidade do texto, tomando como parâmetro analítico os significados emocionais produzidos pelos mesmos. A cor é o primeiro marcador de modalidade e de valores de julgamento que analisaremos nas imagens. Nas orientações de códigos sensoriais que são utilizadas "em contextos nos quais o princípio do prazer é dominante, ou seja, em certos tipos de arte, propagandas, moda, decoração [...], cor é uma fonte de prazer e afetividade, e, consequentemente, nos passa significados de alta modalidade: vermelhos brilhantes, azuis calmantes..." (KRESS \& VAN LEEUWEN, 2006:170). A exemplo da categoria comportamento emocional, sugerimos aqui também a categoria conformidade de aparência ${ }^{8}$, através da qual mapearemos os potenciais de significados veiculados, principalmente, pelas roupas, tendo como base sua conformidade à idade, à posição social e ao estado de afiliação. Por fim, a análise focalizará os significados interpessoais dos anúncios, já que nosso principal interesse é mapear as formas relacionais sobre masculinidade veiculadas na nossa cultura.

A análise nos mostrará, também, que ora um ora outro modo semiótico terá maior importância no design e na produção de significados de emoções nos textos. Assim, tanto os modos semióticos verbais quanto os visuais ganham importância. Um aspecto que fica evidente no corpus aqui estudado é que todos os PR (homens) se encontram sozinhos, situados em ambientes externos e estão sorrindo.

\subsection{Texto publicitário 1: SulAmérica Educaprevi}

O anúncio sobre previdência privada da SulAmérica mostra uma criança como Participante Representado em posição central. No lado esquerdo, acima da imagem, há um texto escrito em letras brancas e abaixo, dentro de um quadro laranja, outro texto seguido da marca da empresa.

8. Essa categoria conformidade de aparência, apesar de ser muito ampla e genérica, permite a análise global do estado semiótico do que se mostra à primeira vista e está relacionada ao conceito linguístico de probabilidade e previsibilidade. Outras categorias mais específicas que expandam e refinem as análises estão sendo desenvolvidas em outra pesquisa sobre os modos semióticos da moda. 


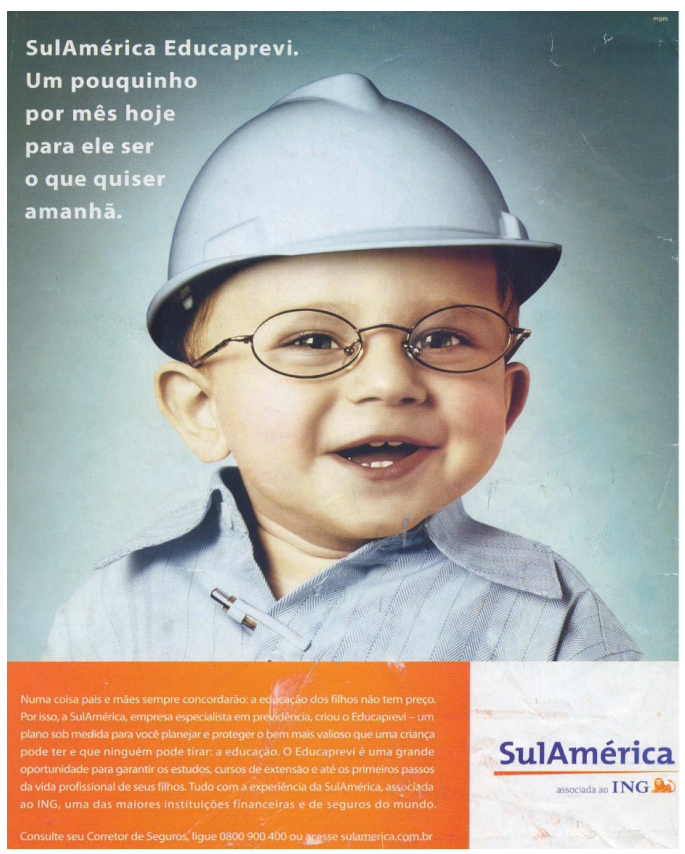

Figura 2: Texto publicitário da SulAmérica Educaprevi.

A criança tem um sorriso entreaberto, o olhar de oferta e está numa posição de distância íntima (entre ele e PI), pois tem um enquadramento em close up. O ângulo da foto é frontal, gerando envolvimento e igualdade de poder entre PI e PR. Tais modos semióticos supõem conteúdos emocionais, já que a proximidade, o envolvimento e o endereçamento articulado pelo olhar e pelo sorriso da criança aproximam o leitor do texto. No decorrer da análise, observaremos que esses modos semióticos serão modificados e produzirão outros significados. No quadro abaixo, sintetizamos o que foi dito acima: 
Quadro 1: Categorias interativas texto publicitário 1

\begin{tabular}{|c|c|c|c|c|c|}
\hline \multirow{11}{*}{$\begin{array}{l}\text { Categorias } \\
\text { Interativas }\end{array}$} & \multirow{2}{*}{$\begin{array}{c}\text { Comportamento } \\
\text { Emocional }\end{array}$} & Alto & Médio & \multicolumn{2}{|c|}{ Baixo } \\
\hline & & & $\mathrm{X}$ & & \\
\hline & \multirow[b]{2}{*}{ Contato } & Demanda & \multicolumn{3}{|c|}{ Oferta } \\
\hline & & & \multicolumn{3}{|c|}{$\mathrm{X}$} \\
\hline & \multirow{2}{*}{$\begin{array}{c}\text { Distância } \\
\text { Social }\end{array}$} & Íntima & Social & \multicolumn{2}{|c|}{ Impessoal } \\
\hline & & $\mathrm{X}$ & & & \\
\hline & \multirow{5}{*}{ Atitude } & Objetiva & \multicolumn{3}{|c|}{ Subjetiva } \\
\hline & & & Envolvimento & \multicolumn{2}{|c|}{ Distanciamento } \\
\hline & & & $\mathrm{X}$ & & \\
\hline & & & Poder do PI & Igualdade & Poder do PR \\
\hline & & & & $\mathrm{X}$ & \\
\hline
\end{tabular}

As cores da propaganda enconcontram-se pouco saturadas e diferenciadas, predominando o azul acinzentado com alta representação de iluminação e sombra com pouco brilho. O que vemos no texto da propaganda são cores pálidas e frias, com tons indeterminados e próximos de um desenho animado produzido através da computação gráfica, tons esses que não transmitem significados de prazer e afetividade (modalização de grau baixo). Fogem, também, às orientações naturalísticas do senso comum dominante na nossa sociedade, aproximando-se da ficção. As roupas utilizadas pela criança - capacete, óculos, camisa social aberta na frente, com uma caneta encaixada - são vestimentas de um adulto, inadequadas para uma criança, e potencializam a atmosfera de baixa modalidade criada pelo sistema de cores e pela conformidade de aparência. No quadro abaixo demonstramos o sistema de baixa modalidade gerado por essas escolhas semióticas. 
Quadro 2: Marcadores de modalidade texto publicitário 1

\begin{tabular}{|c|c|}
\hline \multirow{10}{*}{$\begin{array}{l}\text { Marcadores } \\
\text { de } \\
\text { modalidade } \\
\text { de } \\
\text { cores }\end{array}$} & Saturação \\
\hline & ausência de cores \\
\hline & Diferenciação \\
\hline & 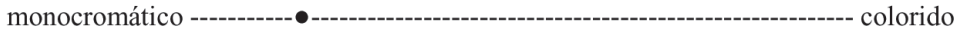 \\
\hline & Modulação \\
\hline & 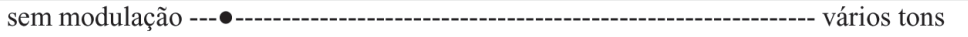 \\
\hline & Iluminação \\
\hline & ausência de luz e sombra ---------------•----alta representação de luz e sombra \\
\hline & Brilho \\
\hline & 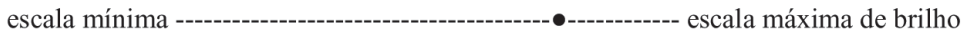 \\
\hline \multirow{2}{*}{$\begin{array}{c}\text { Marcadores } \\
\text { de } \\
\text { modalidade } \\
\text { de } \\
\text { aparência }\end{array}$} & Conformidade de Aparência \\
\hline & 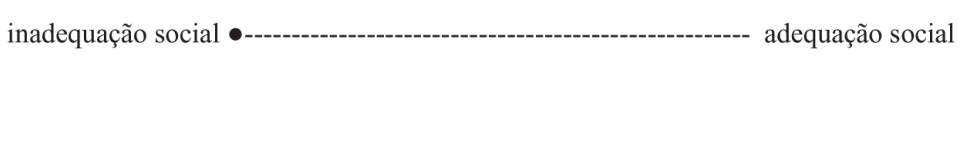 \\
\hline
\end{tabular}

Esses modos semióticos fazem com que o anúncio publicitário tenha baixo nível emocional, apesar do PR ser uma criança (quase um bebê) sorrindo. O significado potencial do sorriso de uma criança tem, no senso comum, o sentido de alta afetividade e emoção dentro de um contexto interativo. Na nossa cultura, é quase impossível não responder ao sorriso de uma criança, que geralmente se configura de forma aberta e espontânea. Entretanto, na imagem desse anúncio, a criança tem um sorriso entreaberto que produz significados com um determinado grau de modalização diferente do que seria o esperado e próprio de uma criança. Além disso, esse texto - que, a princípio, poderia ser julgado como realista - possui uma modalidade visual com baixos valores tanto no plano mimético ( $\mathrm{da}$ representação) quanto no plano semiótico (da significação). Juntos, esses marcadores de modalidade permitem que o texto seja lido e entendido como irreal e pouco emocional.

No texto verbal escrito acima da imagem - SulAmérica Educaprevi. Um pouquinho por mês hoje para ele ser o que quiser amanhã -, o agenciamento se encontra voltado para a criança que pode "ser o que quiser amanhã”, o que produz significados relacionados à escolha da profissão. Tais significados são diminuídos quando observamos as formas de repre- 
sentação da imagem da criança que, de certa forma, controlam o que ele poderá ser: um trabalhador, no modo mais tradicional, uniformizado, homogeneizado. Por outro lado, na parte de baixo, no quadro laranja, no texto "Numa coisa pais e mães sempre concordarão: a educação dos filhos não tem preço", os Participantes "pais e mães" são os Experenciadores do Processo Mental “concordarão”, seguidos da Extensão “a educação dos filhos não tem preço”. Essa forma discursiva transfere o agenciamento para os pais que, concordando com o papel social pré-determinado na imagem, irão adquirir o produto da Educaprevi. Assim, ao seguir a leitura do texto, verificamos que, se, num primeiro momento, o agenciamento parece estar com a criança, posteriormente percebemos um deslocamento dessa função para os pais e para as convenções sociais.

Quando focalizamos as análises com seus significados discursivos, deparamo-nos com as questões relacionadas ao processo de socialização dos homens. Tal processo supõe formas sociais de enquadramento que, no caso dos homens, tradicionalmente estão voltadas para uma ética do trabalho capitalista, como foi apontado por Seidler (1991). Os conteúdos sociais envolvidos na tradicional socialização masculina dizem respeito ao controle das emoções, seguindo uma dinâmica de robotização, ou seja, a configuração de corpos em máquinas sem emoções. A imagem de um trabalhador uniformizado (a criança) alia-se aos princípios de trabalho fordista e taylorista, cujo principal contexto é a padronização, a rotinização e a uniformização dentro de uma relação hierárquica direcionada para a produtividade.

O baixo nível de conteúdos emocionais de todo o texto aponta para o sistema de socialização, no qual são necessários o rebaixamento de sensibilidades e o enquadramento em posturas tradicionais e esperadas de condutas, para que os construtos de masculinidade sejam visualizados como possuidores de determinado grau de poder. Assim, para a masculinidade tradicional, quanto menos emoção demonstrada mais poder social.

\subsection{Texto publicitário 2: Conta universitária e cartão da Caixa}

Na publicidade cujo Participante Representado é o jovem universitário, uma ligação direta é estabelecida com o PI: um sorriso aberto - atitude esperada da criança. Seu sorriso e sua boca num tom avermelhado produzem significados de alegria, felicidade e emoção. O olhar de demanda, aliado 
ao sorriso, cria a expectativa de uma resposta positiva ou negativa de compartilhamento das emoções produzidas pelo autor do texto, ampliando a interação e a produção de significados de suavidade, de afeto e de alegria. Apesar de o adolescente não estar numa posição de centralidade, encontrase numa posição de saliência, de proximidade, em primeira perspectiva, e com enquadramento no ângulo frontal, tendo ao fundo um edifício com muitas janelas, que parece ser uma escola.

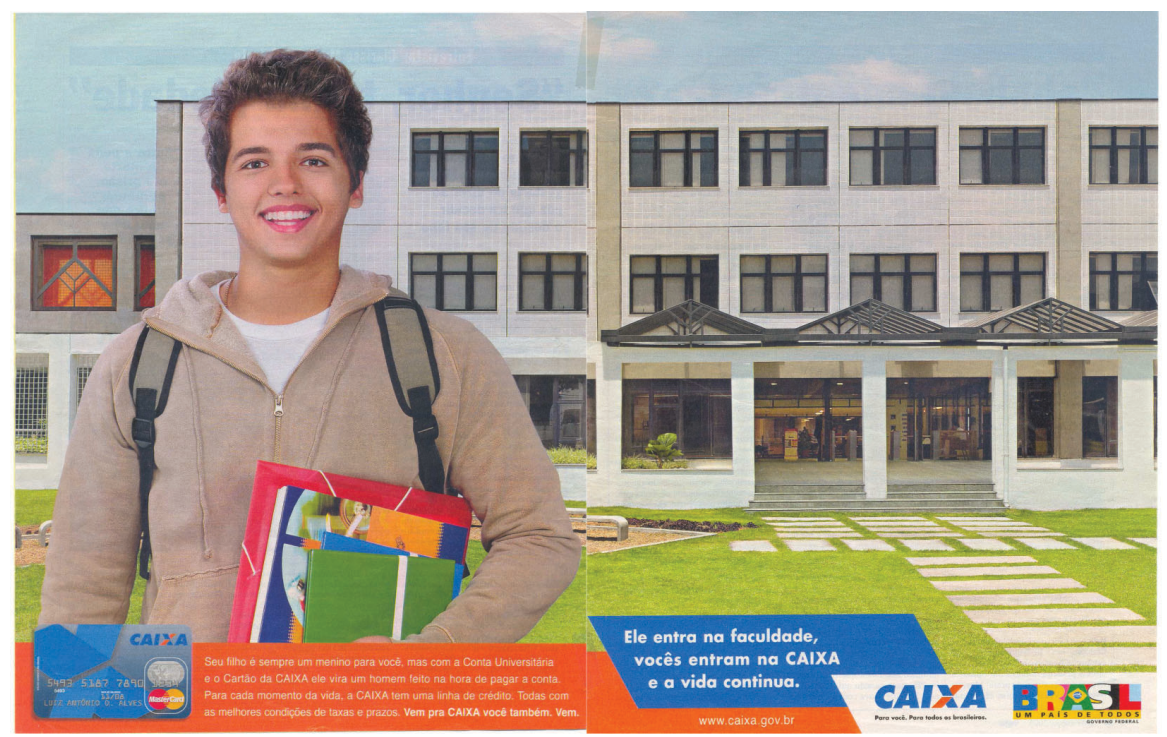

Figura 3: Texto publicitário da Conta universitária e cartão da Caixa.

A utilização desses recursos nos remete a significados de intimidade pessoal com o Participante Interactante e reforça os significados produzidos pelo sorriso e pelo olhar, que esperam do leitor uma resposta de concordância (principalmente pais) quanto à importância do produto vendido (o Cartão da Caixa e a Conta Universitária), o que confirmará os significados de alegria, de felicidade e de emoção. O que nos chama a atenção é que a imagem do adolescente está infantilizada, ou seja, ele se parece com uma criança, ainda distante da fase adulta. O produtor do texto legitima o papel do adolescente enquanto participante principal - aquele que cria intimidade pessoal e proximidade com os leitores/PIs (os pais) do texto visual. Abaixo, segue a síntese das análises visuais das categorias interativas. 
Quadro 3: Categorias interativas texto publicitário 2

\begin{tabular}{|c|c|c|c|c|c|}
\hline \multirow{11}{*}{$\begin{array}{l}\text { Categorias } \\
\text { Interativas }\end{array}$} & \multirow{2}{*}{$\begin{array}{c}\text { Comportamento } \\
\text { Emocional }\end{array}$} & Alto & Médio & \multicolumn{2}{|c|}{ Baixo } \\
\hline & & & $\mathrm{X}$ & & \\
\hline & \multirow[b]{2}{*}{ Contato } & Demanda & \multicolumn{3}{|c|}{ Oferta } \\
\hline & & $\mathrm{X}$ & & & \\
\hline & \multirow[b]{2}{*}{$\begin{array}{l}\text { Distância } \\
\text { Social }\end{array}$} & Íntima & Social & \multicolumn{2}{|c|}{ Impessoal } \\
\hline & & & $\mathrm{X}$ & & \\
\hline & \multirow{5}{*}{ Atitude } & Objetiva & \multicolumn{3}{|c|}{ Subjetiva } \\
\hline & & & Envolvimento & \multicolumn{2}{|c|}{ Distanciamento } \\
\hline & & & $\mathrm{X}$ & & \\
\hline & & & Poder do PI & Igualdade & Poder do PR \\
\hline & & & & $\mathrm{X}$ & \\
\hline
\end{tabular}

Ao observarmos mais diretamente as cores escolhidas para essa publicidade, percebemos que, em comparação com a propaganda anterior, elas estão mais próximas do real, no pólo positivo da estrutura de modalização, segundo Hodge \& Kress (1988). As cores variadas, o sorriso, o olhar e os outros recursos semióticos escolhidos conjugam-se em um efeito altamente afetivo e emocional e isso se deve, principalmente, à proximidade desses modos semióticos com o código naturalístico. $\mathrm{O}$ adolescente carrega uma pasta vermelha, cadernos e livros nas cores verde, azul e laranja em alta saturação, ou seja, são cores vibrantes. O uso do batom com tom brilhante, conjugado com a forma como os cabelos estão cortados e penteados, remetem-nos à imagem do metrossexual fugindo aos padrões da representação masculina tradicional. As roupas apresentam baixa conformidade de aparência, pois se aproximam de formas infantis, destoando da idade do jovem e, consequentemente, do seu estado de afiliação e do papel social relacionado à postura de um universitário. $\mathrm{O}$ texto fica ambíguo, pois o adolescente, parte menino ingênuo e parte metrossexual, veicula alto potencial emocional e afetivo, mas não possui características de agência. Se observarmos o texto verbal, ele focaliza a situação de ação nos pais - possíveis compradores do produto - que têm um filho que "é sempre um menino" e "vira um homem feito na hora de pagar a conta". Essa publicidade reforça a imagem de masculinidade conectada com o espaço exterior, da ação e da conquista, e chama os pais para se alinharem com esse ideal, reforçando o processo de socialização tradicional masculina do menino que se transforma em adulto porque passa a pagar suas contas. 
É interessante observar que a agência é afastada dos conteúdos que têm significado emocional no texto - no caso, o adolescente -, fixando-se nos pais e na instituição que proverá tal acontecimento - a Caixa. Assim, a emoção veiculada também não se apresenta como um estado de poder. No quadro abaixo, encontram-se as representações de modalidade.

Quadro 4: Marcadores de modalidade texto publicitário 2

\begin{tabular}{|c|c|}
\hline \multirow{10}{*}{$\begin{array}{c}\text { Marcadores } \\
\text { de } \\
\text { modalidade } \\
\text { de } \\
\text { cores }\end{array}$} & Saturação \\
\hline & 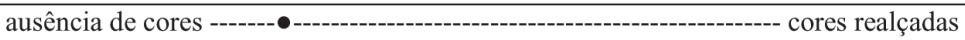 \\
\hline & Diferenciação \\
\hline & 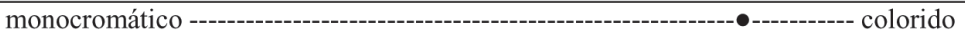 \\
\hline & Modulação \\
\hline & sem modulação ----- \\
\hline & Iluminação \\
\hline & ausência de luz e sombra --------------------•------alta representação de luz e sombra \\
\hline & Brilho \\
\hline & escala mínima ---------------------------------------•----------- escala máxima de brilho \\
\hline Marcadores & Conformidade de Aparência \\
\hline $\begin{array}{l}\text { modalidade } \\
\text { de } \\
\text { aparência }\end{array}$ & inadequação social -- \\
\hline
\end{tabular}

Chama-nos a atenção, no anúncio de um celular da Vivo, que o texto escrito marca o Participante Representado "Carlos Alberto Teixeira", um "Supervisor de vendas da Cooperativa Santa Clara, em Carlos Barbosa no Rio Grande do Sul”, que é identificado com nome e sobrenome, cargo que ocupa e local de trabalho, o que cria significados de status, importância social e poder. 


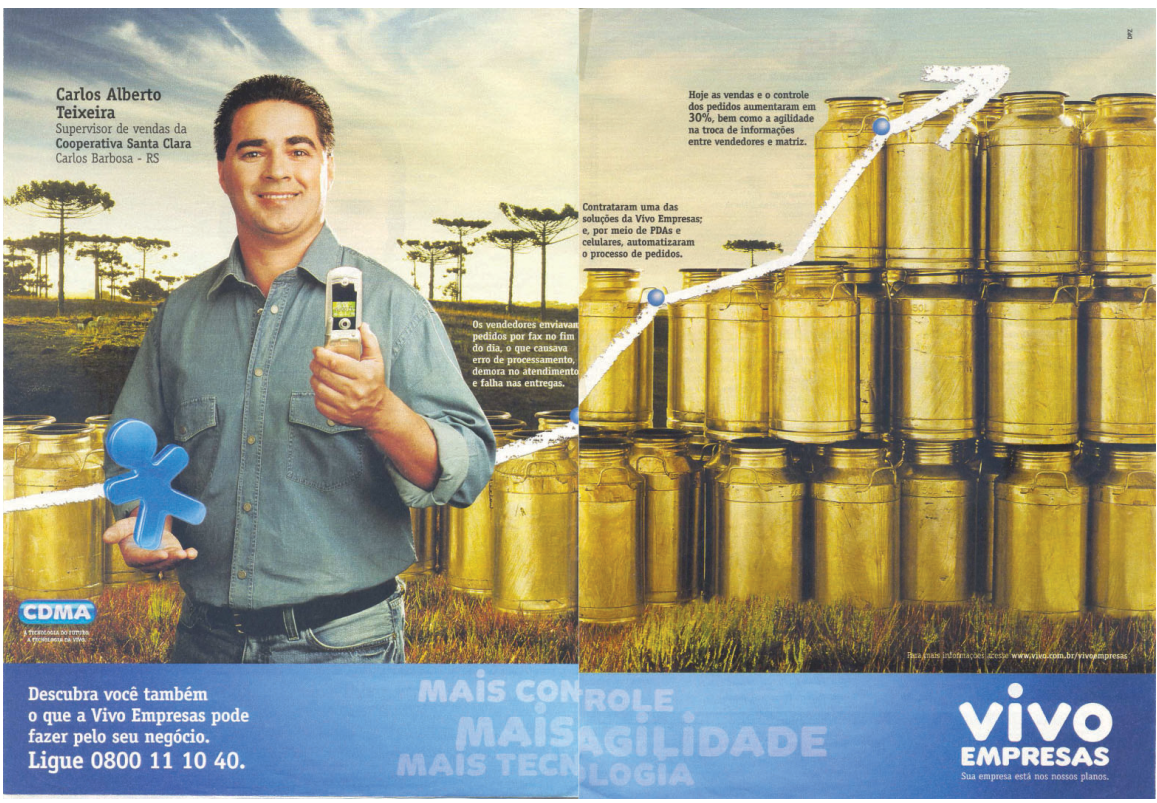

Figura 4: Texto publicitário do Celular da Vivo.

Ele tem um leve sorriso nos lábios, o olhar de demanda, criando contato, e nível médio de comportamento emocional. Ele não está em posição de centralidade, mas de saliência, em ângulo frontal e em primeira perspectiva, o que gera significados de distância social, mas em atitude de envolvimento e igualdade. O homem porta um celular em uma das mãos (a mais elevada) e na palma da outra (a mão que está abaixada) sustenta um símbolo da Vivo. Esses modos semióticos conjugados geram um potencial de significado de oferta de bens e serviços que suscitam uma resposta de concordância, de acordo com a gramática visual. No quadro abaixo, vemos um resumo das categorias interativas. 
Pimenta \& Natividade: Humano, demasiadamente humano ...

Quadro 5: Categorias interativas texto publicitário 3

\begin{tabular}{|c|c|c|c|c|c|}
\hline \multirow{11}{*}{$\begin{array}{l}\text { Categorias } \\
\text { Interativas }\end{array}$} & \multirow{2}{*}{$\begin{array}{c}\text { Comportamento } \\
\text { Emocional }\end{array}$} & Alto & Médio & \multicolumn{2}{|c|}{ Baixo } \\
\hline & & & $\mathrm{X}$ & & \\
\hline & \multirow[b]{2}{*}{ Contato } & Demanda & \multicolumn{3}{|c|}{ Oferta } \\
\hline & & $\mathrm{X}$ & \\
\hline & \multirow{2}{*}{$\begin{array}{l}\text { Distância } \\
\text { Social }\end{array}$} & Íntima & Social & \multicolumn{2}{|c|}{ Impessoal } \\
\hline & & & $\mathrm{X}$ & 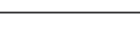 & \\
\hline & \multirow{5}{*}{ Atitude } & Objetiva & \multicolumn{3}{|c|}{$\begin{array}{l}\text { Subjetiva } \\
\end{array}$} \\
\hline & & & \multicolumn{3}{|c|}{ Distanciamento } \\
\hline & & & $X$ & & \\
\hline & & & Poder do PI & \begin{tabular}{|l} 
Igualdade \\
\end{tabular} & Poder do PR \\
\hline & & & & $\mathrm{X}$ & \\
\hline
\end{tabular}

O símbolo da Vivo que o PR segura nas mãos é azul claro, o que, de acordo com os códigos sensoriais, gera significados de calma e suavidade. O brilho no contorno do símbolo aumenta o grau de modalização, distanciando-o do real e do valor de verdade. As roupas do homem seguem também o padrão azul, em conformidade com a aparência esperada para o cargo que ocupa, seu papel social e seu nível de status. Os latões, que estão atrás do $\mathrm{PR}$, em segunda perspectiva, e o gráfico ascendente sobreposto a eles são representados com a cor dourada, configurando um discurso de dinheiro e lucro. Esses latões, que parecem feitos de ouro, vão até o topo da página e se contrapõem ao restante da publicidade, que apresenta cores pálidas e sombreadas, fugindo aos códigos naturalísticos e aproximando-se de uma configuração irreal. 
Quadro 6: Marcadores de modalidade texto publicitário 3

\begin{tabular}{|c|c|}
\hline \multirow{10}{*}{$\begin{array}{c}\text { Marcadores } \\
\text { de } \\
\text { modalidade } \\
\text { de } \\
\text { cores }\end{array}$} & Saturação \\
\hline & 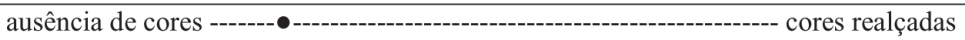 \\
\hline & Diferenciação \\
\hline & monocromático --------------------•------------------------------------------------ colorido \\
\hline & Modulação \\
\hline & sem modulação --- \\
\hline & Iluminação \\
\hline & ausência de luz e sombra -------------------•------alta representação de luz e sombra \\
\hline & Brilho \\
\hline & 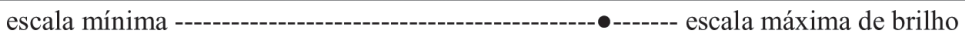 \\
\hline Marcadores & Conformidade de Aparência \\
\hline $\begin{array}{c}\text { de } \\
\text { modalidade } \\
\text { de } \\
\text { aparência }\end{array}$ & inadequação social --- \\
\hline
\end{tabular}

Os modos semióticos conjugados nessa publicidade encontram-se mais próximos dos signos relacionados com o sucesso financeiro. Os aspectos que trazem mais emoção no texto são os latões (de ouro?) conjugados com o gráfico ascendente, principalmente por causa da cor e do brilho. O Participante Representado, com um leve sorriso, não aparece como o elemento afetivo mais importante, pois tal característica encontra-se de forma mais acentuada nos latões de ouro. Trata-se de um discurso altamente empresarial e capitalista, cujo ponto central não está nas relações com pessoas, mas com metas, como foi apontado no quadro que sustenta a publicidade: mais controle, mais agilidade, mais tecnologia. Esse discurso está em total conformidade com os construtos tradicionais da masculinidade que englobam o desenvolvimento de capacidades de controle, competência e, consequentemente, poder social. 


\subsection{Texto publicitário 4: Itaú Private Bank}

No anúncio do Itaú Private Bank, deparamos-nos com a imagem de um executivo sentado no alto de uma ponte.

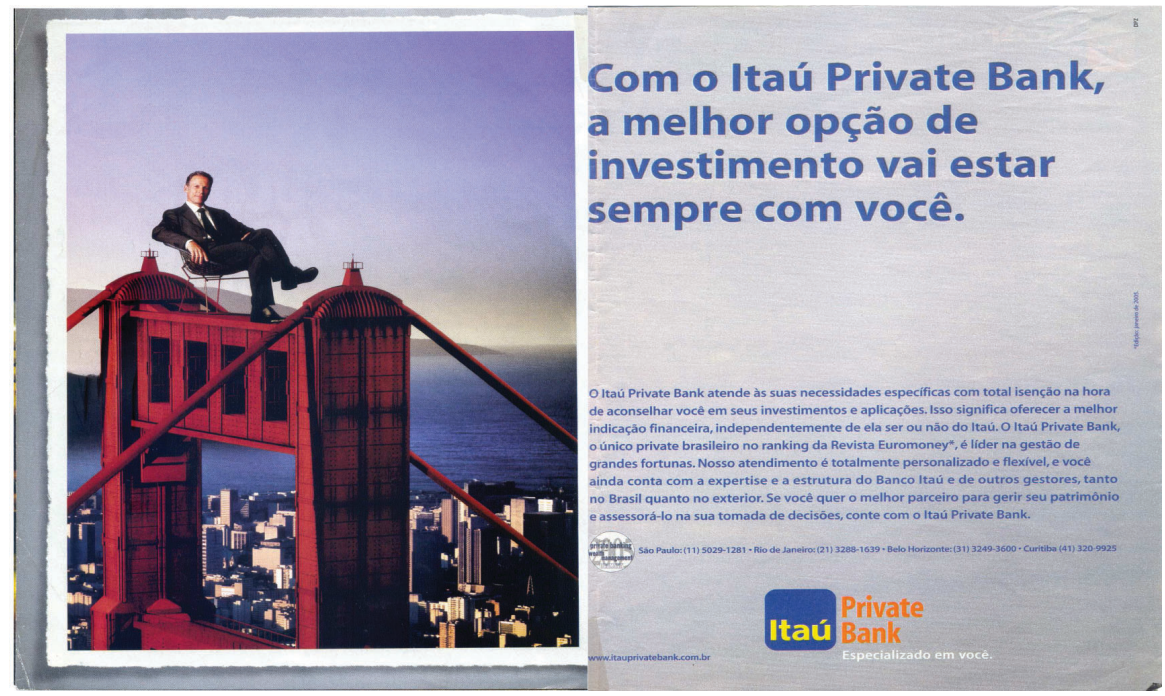

Figura 5: Texto publicitário do Itaú Private Bank.

O Participante Representado sorri de maneira quase imperceptível, sugerindo baixo comportamento emocional e falta de prazer. $\mathrm{O}$ olhar é de demanda e a postura corporal, de oferta, pois o executivo está sentado numa cadeira reclinada, o que gera significados de contemplação do PI. A distância é impessoal, conjugada com a perspectiva em ângulo vertical, de baixo para cima, produzindo significados de distanciamento e alto contexto de poder. No quadro abaixo, demonstramos as categorias interativas. 
Quadro 7: Categorias interativas texto publicitário 4

\begin{tabular}{|c|c|c|c|c|c|}
\hline \multirow{11}{*}{$\begin{array}{l}\text { Categorias } \\
\text { Interativas }\end{array}$} & \multirow[b]{2}{*}{$\begin{array}{c}\text { Comportamento } \\
\text { Emocional }\end{array}$} & Alto & Médio & \multicolumn{2}{|c|}{ Baixo } \\
\hline & & & & \multicolumn{2}{|r|}{$\mathrm{X}$} \\
\hline & \multirow[b]{2}{*}{ Contato } & Demanda & \multicolumn{3}{|c|}{ Oferta } \\
\hline & & & \multicolumn{3}{|c|}{$\mathrm{X}$} \\
\hline & \multirow{2}{*}{$\begin{array}{c}\text { Distância } \\
\text { Social }\end{array}$} & Íntima & Social & \multicolumn{2}{|c|}{ Impessoal } \\
\hline & & & & \multicolumn{2}{|r|}{$\mathrm{X}$} \\
\hline & \multirow{5}{*}{ Atitude } & Objetiva & \multicolumn{3}{|c|}{ Subjetiva } \\
\hline & & & Envolvimento & Distan & ciamento \\
\hline & & & & \multicolumn{2}{|c|}{$\mathrm{X}$} \\
\hline & & & Poder do PI & Igualdade & Poder do PR \\
\hline & & & & & $\mathrm{X}$ \\
\hline
\end{tabular}

O PR veste um terno escuro, gravata e camisa branca, com um tom de solenidade e em conformidade de aparência com um executivo. Esses significados delineiam um Participante que não mostra suas emoções, que não deseja intimidade e envolvimento com o leitor, identificando-se somente com um Participante Interactante que tenha galgado todos os degraus de poder e já esteja no mesmo nível desse executivo: o cliente do Itaú Private Bank.

O executivo é o único que está no plano ideal, no alto da página, e não no plano real, o equivalente à parte de baixo. Sentado de forma confortável, com uma metrópole ao fundo - que não podemos identificar qual é (talvez Nova Iorque ou São Francisco) -, e com as mãos jogadas nos braços da cadeira (que se encontra no alto de uma ponte), o Participante Representado se distancia ainda mais do Participante Interactante, mostrando pouca emoção e afetividade, nenhuma sensibilidade ou suavidade em um ambiente de relação hierárquica de poder.

Discursivamente falando, podemos também entender a mensagem da seguinte forma: se você agir como o Participante da propaganda, terá tanto poder quanto ele. Essa ligação e interação se tornam possíveis uma vez que o Participante lexical escolhido, inúmeras vezes, no texto verbal, é você, estratégia que inclui o leitor, numa tentativa de seduzi-lo para que atue como cúmplice do produto anunciado. Connell (2005) já havia comenta- 
do que a cumplicidade é uma força organizadora da construção social da masculinidade, já que é uma das principais ordens que sustentam a veiculação da hegemonia masculina. Assim, se nem todos os homens cabem nos pressupostos hegemônicos (ser branco, heterossexual, rico etc), a maioria deles mantêm conexões de cumplicidade em um sentido ou outro com tal projeto. Logo, mesmo que nessa publicidade os conteúdos de exclusividade e sucesso estejam disponíveis apenas para alguns, ela conserva seu alto potencial de persuasão, por causa da cumplicidade dos homens com o projeto hegemônico.

Ainda em relação ao poder do Participante Representado, a altura da câmera no momento da foto nos mostra que o ângulo baixo faz com que ele olhe os leitores da imagem de cima para baixo, colocando estes últimos em posição de subordinação. O que nos parece interessante é que a ponte está em ângulo baixo, mais próxima do leitor, criando uma barreira entre o Participante Representado e o Participante Interactante, com alta distância social, o que minimiza a interação e a produção de emoções. Connell (2005) comenta que, se há uma masculinidade hegemônica destinada a alguns e com pressupostos claros e objetivos, existe também uma masculinidade subordinada que serve como contraponto necessário para a manutenção da hegemonia. A subordinação, assim como a posição da ponte, no texto em foco, atua como uma barreira de acesso ao prestígio, prazer e poder destinado a alguns.

As cores são modalizadas e distantes do real ou bem próximas do irreal, fugindo aos códigos naturalistas. $\mathrm{O}$ vermelho da ponte não é vibrante; o céu é cinza e não azul calmante, o que sugere alto grau de modalização e baixo grau de prazer, suavidade, sensibilidade e afetividade. Desse modo, as cores e os outros modos semióticos analisados possuem baixo potencial emocional, deixando espaço para que os signos de poder orientem a mensagem da propaganda. Evidenciamos, assim, um contexto extremo de relação de poder, conjugado com signos altamente hierárquicos: a altura, a posição de distância, a roupa, a impossibilidade de acesso ao PR, o sorriso com baixa intimidade e afetividade. O homem ocupa o topo do mundo com uma expressão de distanciamento e pouca emoção. Essa imagem pode ser considerada a mais hegemônica e racional da construção social da masculinidade tradicional e, como tal, encaixa-se perfeitamente na ética de trabalho capitalista. Seguem abaixo, os marcadores de modalidade. 
Quadro 8: Marcadores de modalidade texto publicitário 4

\begin{tabular}{|c|c|}
\hline \multirow{10}{*}{$\begin{array}{c}\text { Marcadores } \\
\text { de } \\
\text { modalidade } \\
\text { de } \\
\text { cores }\end{array}$} & Saturação \\
\hline & 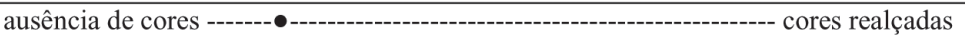 \\
\hline & Diferenciação \\
\hline & 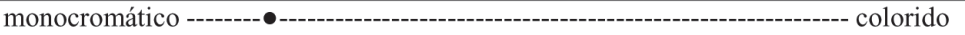 \\
\hline & Modulação \\
\hline & 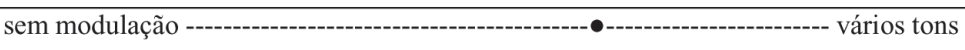 \\
\hline & Iluminação \\
\hline & ausência de luz e sombra --------------------•------alta representação de luz e sombra \\
\hline & Brilho \\
\hline & escala mínima --------------------------------------------•------- escala máxima de brilho \\
\hline \multirow{2}{*}{$\begin{array}{c}\text { Marcadores } \\
\text { de } \\
\text { modalidade } \\
\text { de } \\
\text { aparência }\end{array}$} & Conformidade de Aparência \\
\hline & -------------------------- adequação social \\
\hline
\end{tabular}

Se considerarmos as publicidades aqui analisadas em conjunto, verificaremos que os modos semióticos escolhidos para representar as emoções masculinas e, mais especificamente, o sorriso expressam significados que transmitem poucas emoções e demarcam espaços de poder ora mais ora menos flexíveis. O significado potencial das variadas formas de sorriso, conjugado com os outros modos semióticos, demonstra nesse contexto entendido aqui como a conjugação do contexto de situação e do contexto de cultura - relações e práticas marcadas, poucas vezes, por proximidade e emoção e, na maioria das vezes, por formas instrumentais de poder e distanciamento.

Segundo Kress (2008, 2010), podemos considerar três níveis de análise quando nos deparamos com a produção de significados: estilo, estética e ética. O estilo diz respeito a uma política da escolha. A noção de escolha, ponto central na Linguística Sistêmico-Funcional e na Semiótica Social, diz respeito, em primeira instância, ao sistema linguístico socialmente construído, que possibilita variadas formas de significação, e, em segunda instância, ao potencial que atores sociais têm de escolher formas que consideram mais aptas e plausíveis para a comunicação. A partir desse ponto, o autor postula o segundo nível de análise - a estética - como correspondente à política do 
estilo, ou seja, trata-se das variadas formas relacionadas às escolhas e suas composições. O terceiro nível de análise, denominado ética, está relacionado à política do valor e da avaliação, ou seja, àquilo que consideramos merecedor de destaque e importância.

Pensando na transposição desses níveis de análise para as publicidades descritas neste artigo, verificamos que o estilo e a estética que o sorriso assume, juntamente com outros modos semióticos, estão relacionados mais à ética do poder do que à ética das emoções. Assim, a semiótica dessas publicidades é construída com base em relações sociais de distanciamento, controle das emoções e sucesso profissional, deixando de lado expressões de emoções e sentimentos.

Com base na análise sócio-semiótica que fizemos, consideramos as emoções e a expressão delas como conteúdos social e culturalmente construídos, inseridos em um contexto ideológico e político. Transpondo os significados dessas representações para a vida cotidiana, podemos imaginar a influência delas na construção da subjetividade dos homens e na experiência relacional deles, principalmente com as mulheres e crianças. Sabemos que o sistema simbólico (e hierárquico) que organiza a masculinidade e a feminilidade é fonte de desigualdades em vários campos: a primazia concedida aos homens no acúmulo de riquezas, maiores oportunidades no que tange à participação política, maior acesso aos poderes institucionais, assim como privilégios culturais e sexuais (CONNELL, 2005).

Tais condições persistem por causa do projeto hegemônico de masculinidade que organiza, legitima e corporifica (sorrisos sem emoção, corpos que produzem riquezas e guerras) semióticas de poder e distanciamento emocional. Connell (2005) acrescenta o que chama de "momento de engajamento", ao qual todo homem se submete numa tentativa de alinhamento com o projeto de masculinidade hegemônica. A autora ressalta que o senso de masculinidade se expressa de forma central pelas experiências do corpo, que sugerem o controle das emoções e o desejo heterossexualmente orientado. Ressalta ainda que, de forma contrária, alguns homens passam pelo "momento de separação" da masculinidade hegemônica, cujo tema central transita em torno da renúncia e da passividade. Nesse contexto, há marcadamente duas características a ser desenvolvidas: a primeira relaciona-se à capacidade de ser expressivo e dizer a verdade, especialmente sobre os sentimentos; a segunda refere-se a uma capacidade de ter sentimentos que 
não podem ser facilmente expressos, tais como demonstrar sensibilidade, ter fortes emoções e preocupar-se com pessoas e com a natureza.

Por fim, se consideramos as publicidades como formas instrumentais de construção de identidades, podendo ser consideradas como tecnologias do eu, verificamos que as que foram aqui analisadas fazem parte do projeto de engajamento da masculinidade hegemônica. Elas constroem subjetividades e relações humanas historicamente relacionadas a um sistema de impessoalidade e a formas instrumentais de dominação, além de lançarem essa mensagem para todas as idades e/ou fases mais marcantes da vivência masculina de forma abrangente.

\section{ConsideraÇões finais}

Seguindo o legado de Hodge e Kress (1988), confirmamos, por meio desse artigo - parte de uma pesquisa maior -, que as análises multimodais e sócio-semióticas são instrumentos importantes para o desvelamento de práticas sociais. Através da análise do sorriso, do olhar, das cores, do ângulo, da perspectiva e da posição das imagens dos Participantes Representados nas propagandas analisadas aqui, evidenciamos como a construção da masculinidade se dá nesses anúncios publicitários: criando semióticas de poder e distanciamento emocional.

Se considerarmos as representações midiáticas como um importante espaço de construção de significados sobre identidades sociais, poderemos entender que as publicidades analisadas aqui influenciam a construção da masculinidade de forma altamente hegemônica: distanciada da emoção e voltada para o mundo exterior. Sendo as emoções e os sentimentos fontes importantes de dignidade e integridade humana, ou, como o título deste artigo indica, humano, demasiadamente humano, tal estratégia de distanciamento hierárquica gera uma imagem (e uma prática de subjetivação) de um ser fragmentado e em luta contra si mesmo, na medida em que não integra seus afetos. Podemos realçar a importância de se observar esses conteúdos, pois as emoções, representantes de inumeráveis estados e movimentos humanos, constituem pessoas, relações e práticas políticas, pois elas criam efeitos no mundo.

Nesse sentido, esperamos que as reflexões aqui expostas possam ser aproveitadas para nossas implicações pessoais e políticas nessas representa- 
ções ou, melhor dizendo, para ativar nossa responsabilidade, como atores sociais, para modificar e subverter, principalmente, as práticas de desigualdade e de poder hierárquico entre nossos pares. Além disso, ao buscar reconhecer o que poderia ser chamado de semióticas de (des)codificação da masculinidade hegemônica, ou seja, semióticas contrárias às apresentadas nesse artigo, devemos ficar atentos às formas de expressão de afetos e emoções. Tais semióticas contra-hegemônicas devem produzir sentidos de relações descentradas de si mesmo e, por isso, voltadas para a alteridade, ou seja, o desprendimento do projeto de poder hierárquico (e desigual) que provoca sofrimentos e injustiças nos outros. Com essas reflexões esperamos ter contribuído, de alguma forma, para com os estudos na área da Semiótica Social e da multimodalidade e, ao mesmo tempo, propagar uma posição de ação política e social, pois o fazer crítico nos chama para assumir essa perpectiva e essa responsabilidade.

Recebido em setembro de 2011

Aprovado em dezembro de 2011

E-mail: soniapimenta1@gmail.com

\section{REFERÊNCIAS BIBLIOGRÁFICAS}

ArgYle, Michael. 1975. Bodily Communication. London: Methuen \& Co Ltd.

Argyle, Michael; Cook, Mark. 1976. Gaze and mutual gaze. Cambridge: Cambridge University Press.

Bell, Philip. 2001. Content analyses of visual images In: Jewitt, Carey Van Leeuwen, Theo. Handbook of visual analyses. Sage Publication. London.

ButLer, Judith. 1993. Bodies that matter - on the discursive limits of sex. New York/London: Routledge,.

. 1990. Gender trouble, feminism and the subversion of identity. London: Routledge.

Connell, Robert Willian. 2005. Masculinities. Los Angeles: University of California Press.

Consi, Jorge. et al. 2006. Violencia masculina en la pareja: una aproximación al diagnóstico y a los modelos de intervención. Paidós: Buenos Aires/ Barcelona: México. 
Elias, Norbert. 1991. On human beings and their emotions: a processsociological essay. In: Featherstone, M.; Hepworth, M.; Turner, B. S. The body: social process and cultural theory. London: Thousand Oaks, p.103-125.

Foucault, Michael. 1996. A ordem do discurso. São Paulo: Edições Loyola, . 1988. História da sexualidade. São Paulo: Graal, v. 1: A vontade de saber.

. 1987. Arqueologia do saber. Rio de Janeiro: Forense Universitária. . 1979. Microfísica do poder. São Paulo: Graal.

Giffin, Karen. 2005. A inserção dos homens nos estudos de gênero: contribuições de um sujeito histórico. In: Ciência e Saúde Coletiva. Rio de Janeiro: ABRASCO, 10(1): 47-57.

Hall, Stuart. 1995. Representation: cultural representation and signifying practices. London: Sage.

Hennigen, Inês; Guaresch, Neusa Maria de Fátima. 2002. A paternidade na contemporaneidade: um estudo de mídia sob a perspectiva dos estudos culturais. In: Psicologia E Sociedade; 14(1): 44-68; jan./jun.

Hodge, Robert; Kress, Gunther. 1988. Social semiotics. London: Polity Press.

Kaufman, Michael. 1993. Cracking the armour: power, pain and the lives of men. London: Penguin Books ltd.

Kress, Gunther. 2010. Multimodality: a social semiotic approach to contemporary communication. London/New York: Routledge.

. 2008. Multimodalidade e aprendizagem: novas perspectivas do conbecimento, representação e comunicação. Belo Horizonte: FALE/ UFMG, 2008. Palestra proferida pelo Instituto de Estudos Avançados Transdisciplinares em 14/08/2008. Disponível em http://www.ufmg.br/ ieat/index.php?option $=$ com_content $\&$ task $=$ view $\&$ id $=374 \&$ Itemid $=9$, acesso em 04/11/2008.

Kress, Gunther; van LEEUwEN, Theo. 2006. Reading images: the grammar of visual design. London/New York: Routledge.

. 2001. Multimodal discourse: the modes and media of contemporary communication. London: Arnold publishers.

Matthiessen, Christian. 2006 (mimeo). A Systemic Functional Exploration of the Lexicogrammar of emotion and attitude. In: $33^{\circ}$ International Systemic Functional Congress: SFL and interdisciplinary dialogue: politics, education and business. Universidade Católica, São Paulo, Brasil. p. 1015 jul. 
Oliveira, Pedro. Paulo. 2004. A construção social da masculinidade. Belo Horizonte: Editora UFMG.

Rezende, Cláudia Barcelos. 2002. Mágoas de amizade: um ensaio em antropologia das emoções, Revista Mana, v.8, n. 2: 69-89. Rio de Janeiro. Disponível em: http://www.scielo.br/

scielo.php?script $=$ sci_pdf\&pid $=$ S0104-93132002000200003\&lng $=$ pt\& $\mathrm{nrm}=$ iso\&tlng $=\mathrm{pt}>$. Acesso em: 10 de janeiro de 2007.

SABAT, Ruth. 1999. Quando a publicidade ensina sobre gênero e sexualidade. In Silva, L. H. (Org.). Século XXI: qual conbecimento? qual currículo? Petrópolis: Vozes: 244-261. 